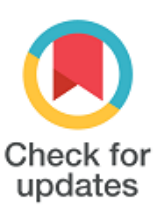

DOI: $10.21859 /$ ijcp -404

\section{Thrombophilia in Pregnancy}

\section{Cristina Hotoleanu ${ }^{1, *}$}

${ }^{1} \mathrm{MD}, \mathrm{PhD}$, Department 5, Iuliu Hatieganu University of Medicine and Pharmacy, Cluj-Napoca, Romania

${ }^{*}$ Corresponding author: Cristina Hotoleanu, 8 Babes Street, 400012, Cluj-Napoca, Romania, Tel: +40-264597256; E-mail: cristinaiga@yahoo.com, chotoleanu@umfcluj.ro

\begin{tabular}{l} 
Submitted: 07-03-2019 \\
Accepted: 31-03-2019 \\
\hline Keywords: \\
Pregnancy \\
Thrombophilia \\
Venous Thromboembolism \\
Venous Thrombosis \\
\hline C) 2019. International Journal of \\
Cardiovascular Practice.
\end{tabular}

\section{Abstract}

Pregnancy represents a physiologic hypercoagulable state. The presence of inherited thrombophilias (factor V Leiden, prothrombin G20210A mutation, deficiencies of protein $\mathrm{C}$, protein $\mathrm{S}$ and antithrombin) or acquired thrombophilias (antiphospholipid syndrome) increases the risk for venous thromboembolism, which represents one of the most common causes of direct maternal death. The clinical diagnosis of thrombosis can be difficult because of the overlap of symptoms with pregnancy-related manifestations. Antiphospholipid syndrome is correlated with early and late pregnancy complications whereas the association between the inherited thrombophilias and adverse pregnancy outcomes is still controversial. The psychological impact of thrombophilia in pregnancy should be also taken into consideration to prevent the negative effects of anxiety and stress on mother's health and on birth outcomes. Thrombophilia testing in pregnancy is recommended only in cases in which the result is likely to influence the therapeutic decision. Low-molecular-weight heparins are the preferred anticoagulant for prophylaxis and therapy of thromboembolic events in pregnancy, presenting a low incidence of side effects. Future research is required to establish the optimal therapeutic strategy in pregnant women with thrombophilia, based upon a better stratification, in order to prevent thromboembolism and to improve pregnancy outcomes.
\end{abstract}

\section{INTRODUCTION}

Thrombophilia or hypercoagulability, defined as the tendency to develop thrombosis, can be secondary to hereditary and acquired causes. The physiologic prothrombotic changes and the additional effect of thrombophilic factors represent commonly the background of pregnancy-related thrombosis. 1 Inherited thrombophilia is a consequence of a loss of function mutations (which result in reduced or abolished protein function) such as deficiencies of antithrombin, protein $\mathrm{C}$, protein $\mathrm{S}$, and/or a gain of function mutations (which result in new or enhanced protein activity) such as prothrombin G20210A mutation and Factor V Leiden (FV Leiden). Although some studies have shown the contribution of inherited thrombophilia to an adverse pregnancy outcome (e.g. preeclampsia, placental abruption, intrauterine growth delay, fetal loss) the association is still controversial. The main acquired thrombophilia associated with an increased thrombotic risk and pregnancy complications such as recurrent fetal loss, fetal death, preeclampsia and intrauterine growth restriction, is represented by the anti-phospholipid syndrome (APS) [1].

The purpose of this paper is to review the effects of thrombophilia in pregnancy (the increased thrombotic risk, adverse pregnancy outcomes, and psychological impact) and the strategies for thromboprophylaxis and therapy.

\section{Pregnancy Morbidity and Mortality Associated With Thrombosis}

Pregnancy is associated with a 5-10 fold increased risk of venous thromboembolism (VTE); the risk is highest immediately postpartum being about 20 -fold greater than that of non-pregnant women [2]. The incidence of VTE is estimated to be approximately $0.5-2.2 / 1000$ deliveries [2]. A recent prospective cohort study that included 1.3 million pregnant women identified the following risk factors for pregnancy-related VTE: increased maternal age, hyperemesis, multiple gestation, infection, hospitalization and obesity [3]. A prior episode of VTE also significantly increases the thrombotic risk in pregnancy, with an estimated rate of VTE recurrence of $10.9 \%$ [1].

VTE, including both deep venous thrombosis (DVT) and pulmonary embolism (PE) is potentially lifethreatening condition. The World Health Organization mortality database found embolism accounts for $3.2 \%$ of 
global maternal deaths [4]. VTE is the leading cause of direct maternal death in the United Kingdom and one of the most common causes in the European Union, according to EURO-PERISTAT project, which includes reports from 26 European countries [5, 6]. A recent observational study, that used data from the Pregnancy Mortality Surveillance System, shows that the 2011-2013 pregnancy-related mortality ratio was 17.0 deaths/ 100,000 live births in the United States and VTE accounted for $9.2 \%$ of all pregnancy-related deaths [7].

\section{Physiopathology of Prothrombotic State during Pregnancy}

Hypercoagulability, venous stasis and vessel damage known as Virchow's triad- represent the mechanisms leading to the occurrence of VTE. The hypercoagulable state in pregnancy, representing an adaptive transient mechanism in preparation for hemostasis during birth, results from a progressive increase in the levels of Factors VII, VIII, X and fibrinogen throughout pregnancy, with a peak at delivery, and a decrease in protein S, antithrombin and fibrinolysis [8]. An acquired activated protein $C$ resistance may be found in $40 \%$ of pregnant women. D-dimer levels, with a threshold of $1.0 \mathrm{mg} / \mathrm{L}$ up to week 30 of pregnancy and, respective, $2.0 \mathrm{mg} / \mathrm{L}$ just prior to delivery, peaks on the first day postpartum and then decrease, indicating that the coagulation and fibrinolytic systems begin to return to the baseline [9]. However, a procoagulant state lasts for 6-8 weeks after giving birth or longer, up to 12 weeks postpartum $[8,9]$.

Venous stasis is due to several mechanisms such as: the vasodilatation induced by pregnancy-related hormones, decreased venous tone, increased venous pressure, reduced venous flow velocity and compression of the left iliac vein $[10,11]$. The supine position may also lead to the compression of the inferior cava vein by the enlarged uterus. The improvement of venous outflow and capacitance occurs usually 3 months postpartum. Pelvic veins may suffer a degree of endothelial damage during the vaginal or caesarian delivery [11].

\section{Clinical Implications of Thrombophilia in Pregnancy}

\section{VTE}

Pregnancy-related VTE is manifested as DVT in 75$80 \%$ of the cases; an underlying thrombophilic factor may be found in half of these situations [1, 11]. Hereditary thrombophilia increases the thrombotic risk in pregnancy up to 34-fold [12]. DVT presents two peculiar aspects in pregnancy: it occurs predominantly in the left lower limb (90\% versus 55\% in non-pregnant women) and especially at the proximal level ( $72 \%$ at the iliofemoral veins versus vs. $9 \%$ in non-pregnant women) leading to an increased risk of PE [11].11 DVT episodes, equally distributed across the three trimesters of pregnancy, occur in prenatal period in two thirds of the cases [11].

PE may occur in $20-25 \%$ of women who have untreated DVT and may be fatal in $15 \%$ of pregnant women, of whom $66 \%$ may die within half an hour from the thromboembolic event [13].

Based on the relative thrombotic risk, the inherited thrombophilias have been classified as: low-risk thrombophilias such as heterozygosity for FV Leiden, heterozygosity for prothrombin G20210A mutation, deficiencies of protein $\mathrm{S}$ and $\mathrm{C}$, and high-risk thrombophilias: homozygosity for FV Leiden, homozygosity for prothrombin G20210A mutation, compound heterozygosity for FV Leiden and prothrombin mutation, and antithrombin deficiency [1]. However, a recent systematic review and metaanalysis has shown that protein $\mathrm{C}$ and protein $\mathrm{S}$ deficiencies represent high risk thrombophilias in pregnancy whereas the compound heterozygosity for FV Leiden and prothrombin G20210A mutation present a lower absolute risk of VTE [12].

Other inherited thrombophilias, methylenetetrahydrofolate reductase polymorphisms C677T and A1298C, leading to hyperhomocysteinemia, are not associated with VTE in pregnancy, partly explained by the routinely administration of folic acid supplements which reduce homocysteinemia $[1,8]$.

FV Leiden and protrombin G20210A mutation represent the most common inherited thrombophilias (with the highest prevalence in South Europe) whereas protein $S$, protein $C$ and antithrombin deficiencies are rare in general population $[1,14]$. The genetic background, the prevalence and the pregnancy-related thrombotic risk of inherited thrombophilias are summarized in Table 1.

The diagnosis of VTE is difficult, because of the overlap of symptoms with those which are commonly pregnancy-related: pain and edema of the lower limb, tachycardia and dyspnea $[10,15]$. The pretest probability of DVT in pregnancy is assessed using the "LEFt" decision rule, based upon the presence of the following symptoms: left leg location, edema with at least $2 \mathrm{~cm}$ circumference difference between calves and the occurrence in the first trimester [10]. Compression duplex ultrasound is the primary diagnostic test for DVT; in case of suggestive symptoms and negative findings, the test should be repeated or, if the results are equivocal and iliac vein thrombosis is suspected, magnetic resonance imaging or venography are recommended $[13,16]$. Recent data show that the exposure to MRI is safe during the first trimester of pregnancy whereas gadolinium MRI at any time of pregnancy is associated with an increased risk of harm to the fetus, stillbirth or neonatal death [17]. The measurement of D-dimer, increased with large individual fluctuation during pregnancy, is not 
recommended as a screening tool to exclude VTE in pregnancy $[9,13,16]$.

The clinical diagnosis of $\mathrm{PE}$ is suggested by the sudden occurrence of symptoms such as: dyspnea, pleuritic chest pain, tachypnea, tachycardia, unexplained hypotension, hemoptysis, cough. When PE is suspected and in the presence of manifestations of DVT, duplex ultrasound of the lower limbs is indicated and the anticoagulant therapy should be administrated if the result is positive; in the absence of manifestations of DVT or a negative result, a ventilation/perfusion lung scan or a computerized tomography pulmonary angiogram should be performed, according to the recent guidelines $[13,16]$. Although chest $\mathrm{X}$-rays findings are not specific or sensitive for $\mathrm{PE}$, the examination is useful for the pregnant women. The selection of women with normal results at chest X-rays for ventilation/perfusion scan increases the rate of diagnostic result comparatively to computerized tomography pulmonary angiogram (94\% versus $70 \%$ ) whereas those with abnormal chest $\mathrm{X}$-rays present higher non-diagnostic result rate with ventilation/perfusion scan than computerized tomography pulmonary angiogram (40\% versus $16.4 \%$ ) $[13,16]$. Although the fetal exposures are below the threshold for malformations 100-200 mGy, computerized tomography pulmonary angiogram is associated with a relatively high dose of radiation to the mother's breast tissue, leading to an increase of the lifetime risk of breast cancer by $13.6 \%[11,13]$. The ventilation/perfusion scan should be recommended for young women with a family history of breast cancer or previous chest computerized tomography [13].

Table 1. Inherited Thrombophilias: Genetic Background, Prevalence and Pregnancy-Related Risk of VTE

\begin{tabular}{|c|c|c|c|c|}
\hline Thrombophilia & Genetic background & $\begin{array}{l}\text { Prevalence in } \\
\text { healthy population } \\
(\%)[1,13]\end{array}$ & $\begin{array}{c}\text { Relative risk of } \\
\text { pregnancy-related VTE } \\
(\%)[1,2]\end{array}$ & $\begin{array}{l}\text { Absolute risk of } \\
\text { pregnancy-related } \\
\text { VTE (\%) [12] }\end{array}$ \\
\hline FV Leiden & $\begin{array}{l}\text { Guanine to adenine substitution at } \\
\text { nucleotide } 1691 \text { in the FV gene }\end{array}$ & $1-15$ & $\begin{array}{l}\text { Homozygous } 34.4 ; \\
\text { Heterozygous } 8.3\end{array}$ & $\begin{array}{l}\text { Homozygous 6.2; } \\
\text { heterozygous } 1.1\end{array}$ \\
\hline $\begin{array}{l}\text { Prothrombin } \\
\text { G20210A }\end{array}$ & $\begin{array}{l}\text { Guanine to adenine substitution at } \\
\text { nucleotide } 20210 \text { in the } 3^{\prime} \\
\text { untranslated region of the } \\
\text { prothrombin gene }\end{array}$ & $0.2-3$ & $\begin{array}{c}\text { Homozygous } 26.3 ; \\
\text { Heterozygous } 6.8\end{array}$ & $\begin{array}{c}\text { Homozygous; } \\
\text { Heterozygous } 0.9\end{array}$ \\
\hline $\begin{array}{l}\text { Protein C } \\
\text { deficiency }\end{array}$ & $\begin{array}{l}\text { Mutations leading to a quantitative } \\
\text { deficiency (type I) or functional } \\
\text { deficiency (type II). }\end{array}$ & 0.2 & 4.8 & 7.8 \\
\hline $\begin{array}{l}\text { Protein S } \\
\text { deficiency }\end{array}$ & $\begin{array}{l}\text { Mutations leading to decreased levels } \\
\text { or impaired function }\end{array}$ & $0.03-0.13$ & 3.2 & 4.8 \\
\hline $\begin{array}{l}\text { Antithrombin } \\
\text { deficiency }\end{array}$ & $\begin{array}{l}\text { Mutations leading to decreased levels } \\
\text { (type I of deficiency) or reduced } \\
\text { activity (type II of deficiency) }\end{array}$ & $0.02-0.2$ & 4.7 & 16.6 \\
\hline
\end{tabular}

Abbreviations: VTE: venous thromboembolism, FV Leiden: Factor V Leiden

The electrocardiogram may be more useful for the diagnosis of $\mathrm{PE}$ in pregnancy than in non-pregnant patients, since almost half of the pregnant women with acute PE present abnormalities such as: inverted $\mathrm{T}$ wave, S1Q3T3 pattern and right bundle branch block [11]. The arterial blood gas measurements are of limited value in pregnancy-related VTE, showing often normal results in the absence of massive $\mathrm{PE}[11,13]$.

\section{Adverse Pregnancy Outcomes}

Although numerous case-control studies have shown a link between inherited thrombophilia and adverse pregnancy outcomes such as: pre-eclampsia, placental abruption, fetal growth restriction, stillbirth and recurrent pregnancy loss, prospective cohort studies failed to confirm a cause-effect association. A weak association has been found between FV Leiden, prothrombin mutation, protein $S$ deficiency and $2^{\text {nd }}$ or $3^{\text {rd }}$ trimester pregnancy loss as well as for FV Leiden, prothrombin mutation and recurrent 1 st trimester loss $[1,11,14]$.

APS is the most important acquired thrombophilic factor manifested with recurrent venous and arterial thromboses and/or early and late pregnancy complications (recurrent miscarriage, fetal growth restriction, preeclampsia, premature birth, oligohydramnios, placental insufficiency and intrauterine death) along with persistent antiphospholipid antibodies including lupus anticoagulant, anti- $\beta 2$-glycoprotein I, and/or anti-cardiolipin antibodies [18]. Although venous thrombosis is located mainly at the lower limbs, it may occur in unusual territories. Lupus anticoagulant presents the strongest association with thrombosis; the estimated relative risk of VTE for pregnant women with APS is 15.8 [1]. It has been shown that immunoglobulin G anti$\beta 2$ glycoprotein I-domain 1 antibodies are associated with an increased thrombotic risk and obstetrical complications [18].

The pregnancy morbidity in women in the absence of thrombotic manifestations and/or history of thrombosis defines the obstetric APS. Catastrophic APS, the most severe form of APS, may also occur in pregnancy and postpartum and is manifested with multiple thromboses and multiorgan failure [18]. 


\section{Thromboprophylaxis in Pregnancy}

It has been shown that universal as well as selective thrombophilia screening, except for antiphospholipid syndrome, is not cost-effective for placenta-mediated pregnancy complications $[19,20]$. Ideally, thrombophilia should be tested when the patient is not pregnant, does not have an acute VTE, before the administration of anticoagulants and when the results are likely to influence the medication $[2,16,20]$.

Thromboprophylaxis in pregnancy should be considered in cases with thrombotic risk high enough to benefit from this therapy $[2,19,20]$. The factors contributing to an increased risk of VTE include: personal and family history of VTE, thrombophilia, prolonged immobilization, obesity, pregnancy complications and medical co-morbidities [2, 16, 19]. There is no firm recommendation regarding thromboprophylaxis in pregnancy, since the lack of consensus of the current guidelines [2, 12]. Considering the patient-centered medical approach, an individual risk-benefit is recommended to be assessed, taking also into account the patient's preferences [2].
Based on recent data, thromboprophylaxis in pregnancy may be recommended in cases with family history of VTE and deficiency of antithrombin, protein $\mathrm{C}$, or protein $S$ as well as in women homozygous for FV Leiden with a positive family history and additional risk factors for VTE [12].

Thromboprophylaxis should be commenced early in the pregnancy and continued up to 6 weeks postpartum with anticoagulants that do not cross placenta, such as unfractionated heparin or low-molecular-weight heparin $(\mathrm{LMWH})$ which presents a better safety profile [13, 16, 19]. Vitamin $\mathrm{K}$ antagonists cross the placenta and may affect the fetus (resulting in coumarin embryopathy and increased risk of intracranial hemorrhage before birth) and therefore they should not be administrated in pregnancy; the risk of embryopathy is eliminated if the medication is discontinued before the 6 th week of gestation [2]. The recommended prophylactic and therapeutical doses of LMWH are summarized in Table 2. High risk situations such as APS may require the administration of intermediate doses that can be double than prophylactic doses [2].

Table 2. Prophylactic and Therapeutic Doses of LMWH $[13,16,19]$

\begin{tabular}{|lcc|}
\hline LMWH & Prophylactic doses & Therapeutic doses \\
Dalteparin & 5000 Uw once daily & $200 \mathrm{U} / \mathrm{kg}$. once daily or 100U/kg. twice daily \\
Tinzaparin & $4500 \mathrm{U}$ once daily & $175 \mathrm{U} / \mathrm{kg}$ once daily \\
Enoxaparin & $40 \mathrm{mg}$ once daily & $1 \mathrm{mg} / \mathrm{kg} \mathrm{mg} \mathrm{twice} \mathrm{daily}$ \\
Nadroparin & 2850 U once daily & $171 \mathrm{U} / \mathrm{kg}$ once daily or $86 \mathrm{U} / \mathrm{kg}$. twice daily \\
\hline
\end{tabular}

Abbreviation: LMWH: low-molecular-weight heparin

Mechanical prophylaxis with elastic stockings or intermittent pneumatic compression may be considered in hospitalized women when LMWH are contraindicated. Although it has been shown that thromboprophylaxis decreases the risk of VTE in pregnancy, recent data of a systematic review reveal that LMWH do not appear to influence the risk of recurrent placenta-mediated pregnancy complications: preeclampsia, late pregnancy loss, and birth of a small-forgestational-age neonate; however, the same study shows that $\mathrm{LMWH}$ decreases the risk of recurrent placental abruption in at-risk women [21].

\section{Treatment of Pregnancy-Related VTE}

The occurrence of an episode of VTE in pregnancy requires promptly therapeutic anticoagulation with LMWH; there is no consensus regarding the optimal doses and the timing of administration: once or twice daily [2]. Although the increase in glomerular filtration rate and in patient's weight during pregnancy may justify the adjustment of LMWH dose, many studies have shown that few pregnant women require this in order to maintain proper anti-Xa levels. The monitoring of anti$\mathrm{Xa}$ levels is not routinely indicated and should be performed only in women with renal failure and in those with morbid obesity or very low weight [13].
Therapeutic doses of LMWH are effective in pregnancyrelated VTE, with an associated risk of recurrent VTE of $1.15 \%$ [11]. The once-daily LMWH dosing schedule does not appear to be associated with a higher risk of VTE recurrence comparatively to twice-daily regimen [2]. There is no data showing a greater efficiency of one LMWH comparatively to others $[2,16,19]$. In case of renal impairment, Enoxaparin is the LMWH of choice; in severe cases with a creatinine clearance less than 30 $\mathrm{mL} / \mathrm{min}$, unfractionated heparin is recommended [2]. The minimum duration of the anticoagulation with LMWH is usually 3 months in pregnancy and 6 weeks postnatal [2]. The therapeutic dose of LMWH can be maintained throughout this period or it could be reduced to an intermediate dose after several weeks (less than $75 \%$ of a full dose but greater than prophylactic dose), especially in case of distal DVT or in women at risk of hemorrhage and osteoporosis [2].

The therapy may be adjusted based on individual risk factors such as cesarean delivery, immobility, obesity, obstetric complications, previous VTE, family history of VTE [16]. LMWH are associated with a lower risk of side-effects (bleeding, osteoporosis, heparin-induced thrombocytopenia) compared with unfractionated heparin $[2,13]$. 
Unfractionated heparin is administrated in pregnant patients with massive $\mathrm{PE}$ and in those with severe renal impairment, initially as a bolus intravenous $80 \mathrm{U} / \mathrm{kg}$, followed by continuous infusion $18 \mathrm{U} / \mathrm{kg}$ and adjusted for an activated partial thromboplastin time at 1.5-2.5 times baseline; the therapy continues either with unfractionated heparin administrated subcutaneously $150-200 \mathrm{U} / \mathrm{kg}$ twice daily either with LMWH in therapeutic doses [13, 16, 19].

The new oral anticoagulants, such as direct thrombin inhibitors (dabigatran), and factor $\mathrm{Xa}$ inhibitors (rivaroxaban, apixaban, and edoxaban) may cross the placenta and should be avoided in pregnancy $[13,16]$. Danaparoid and fondaparinux are heparanoid molecules and may be a therapeutic option for pregnant women with allergy to heparins or heparin-induced thrombocytopenia $[11,16]$.

Thrombolytic therapy with streptokinase, r-tPA or urokinase is indicated only in life-threatening VTE, e.g. massive PE with hemodynamic instability $[13,16]$. Vena cava filters are rarely used in pregnant women and may be considered in case of acute PE within 2 weeks after delivery or recurrent VTE despite therapeutic anticoagulation [11].

The use of graded compression stockings in pregnant women with DVT may be indicated for the relief of the symptoms; recent studies failed to prove the benefit in the prevention of the post-thrombotic syndrome and the decrease in the recurrence rate of VTE in nonpregnant patients $[13,16]$.

\section{Psychosomatic Perspective}

Thrombophilia in pregnant women is also associated with an important psychological impact and requires counseling about the increased risk of thrombosis and possible adverse pregnancy outcome [20]. Pregnant women coping with thrombophilia face difficulties because of the emotional component of the diagnosis and treatment (fear, anxiety), associated with the sense of uncertainty and the need for professional support [22].

There is growing evidence that negative affective states (anxiety, depression) and stress exposure of the mother during pregnancy have implications on the birth outcomes (e.g. preterm birth, low birth weight) as well as on the child's subsequent neurodevelopment and health [23]. The identification of the signs of depression and/or anxiety should be also taken into consideration in the assessment of thrombophilia and pregnancyrelated VTE.

The management of thrombophilia and VTE in pregnancy is complex and may require a multidisciplinary team involving obstetrician, midwife, geneticist, cardiologist, psychologist $[13,24]$.

\section{Future Directions}

Further studies are required in order to clarify the optimal therapeutic strategy in pregnant women with thrombophilia, in order to prevent and treat VTE as well as to improve the pregnancy outcome. The ongoing randomized controlled trials may offer some pertinent answers: the Highlow study and ALIFE2 study, which investigate two dosing regimens of $\mathrm{LMWH}$ in pregnant women with a history of VTE, respective the effect of LMWH on live birth in patients with inherited thrombophilia and history of at least two miscarriages [25]. Although it has been shown that inherited thrombophilia has no significant contribution to adverse pregnancy outcomes, the complex physiopathologic mechanisms of this relationship are not completely clarified. Research is required to identify possible biomarkers (e.g. ANXA5 M2 haplotype) for the stratification of the risk and a better-targeted antithrombotic therapy $[8,20]$. Further investigations may take also into consideration the bio-psychosocial model, to detect better the symptoms of anxiety, depression and stress in pregnant women with thrombophilia, which may overlap, creating difficulties in screening and intervention.

\section{CONCLUSIONS}

Thrombophilia in pregnancy represents a complex condition associated with increased risk of VTE and psychological implications. However, thrombophilia testing in pregnancy is recommended only when the results may influence the therapeutical decision. Further studies are required to release firm recommendations for thromboprophylaxis and anticoagulant therapy in pregnancy-related VTE.

\section{REFERENCES}

1. Battinelli EM, Marshall A, Connors JM. The role of thrombophilia in pregnancy. Thrombosis. 2013;2013:516420. doi: $10.1155 / 2013 / 516420$ pmid: 24455235

2. Bates SM, Middeldorp S, Rodger M, James AH, Greer I. Guidance for the treatment and prevention of obstetricassociated venous thromboembolism. J Thromb Thrombolysis. 2016;41(1):92-128. doi: 10.1007/s11239-0151309-0 pmid: 26780741

3. Virkus RA, Lokkegaard E, Lidegaard O, Langhoff-Roos J, Nielsen AK, Rothman KJ, et al. Risk factors for venous thromboembolism in 1.3 million pregnancies: a nationwide prospective cohort. PLoS One. 2014;9(5):e96495. doi: 10.1371/journal.pone.0096495 pmid: 24788753

4. Say L, Chou D, Gemmill A, Tuncalp O, Moller AB, Daniels J, et al. Global causes of maternal death: a WHO systematic analysis. Lancet Glob Health. 2014;2(6):e323-33. doi: 10.1016/S2214-109X(14)70227-X pmid: 25103301

5. Nair M, Knight M. Maternal Mortality in the UK 2011-13: Surveillance and Epidemiology. In: Knight M, Tuffnell D, Kenyon S, Shakespeare J, Gray R, Kurinczuk JJ, editors. On behalf of MBRRACE-UK Saving Lives, Improving Mothers' Care - Surveillance of maternal deaths in the UK 2011-13 and lessons learned to inform maternity care from the UK and Ireland Confidential Enquiries into Maternal Deaths and Morbidity 2009-13. London: Oxford, National Perinatal Epidemiology Unit, University of Oxford 2015.

6. Bouvier-Colle MH, Mohangoo AD, Gissler M, Novak-Antolic Z, Vutuc C, Szamotulska K, et al. What about the mothers? An analysis of maternal mortality and morbidity in perinatal health surveillance systems in Europe. BJOG. 2012;119(7):880-9; 
discussion 90. doi: 10.1111/j.1471-0528.2012.03330.x pmid: 22571748

7. Creanga AA, Syverson C, Seed K, Callaghan WM. PregnancyRelated Mortality in the United States, 2011-2013. Obstet Gynecol. 2017;130(2):366-73. doi: 10.1097/AOG.000000 0000002114 pmid: 28697109

8. Ormesher L, Simcox L, Tower C, Greer IA. Management of inherited thrombophilia in pregnancy. Womens Health (Lond). 2016;12(4):433-41. doi: 10.1177/17455057166537 02 pmid: 27638899

9. Hedengran KK, Andersen MR, Stender S, Szecsi PB. Large DDimer Fluctuation in Normal Pregnancy: A Longitudinal Cohort Study of 4,117 Samples from 714 Healthy Danish Women. Obstet Gynecol Int. 2016;2016:3561675. doi: 10.1155/2016/3561675 pmid: 27190521

10. Soma-Pillay P, Nelson-Piercy C, Tolppanen H, Mebazaa A. Physiological changes in pregnancy. Cardiovasc J Afr. 2016;27(2):89-94. doi: 10.5830/CVJA-2016-021 pmid: 27213856

11. Simcox LE, Ormesher L, Tower C, Greer IA. Pulmonary thrombo-embolism in pregnancy: diagnosis and management. Breathe (Sheff). 2015;11(4):282-9. doi: 10.1183/20734735.0 08815 pmid: 27066121

12. Croles FN, Nasserinejad K, Duvekot JJ, Kruip MJ, Meijer K, Leebeek FW. Pregnancy, thrombophilia, and the risk of a first venous thrombosis: systematic review and bayesian metaanalysis. BMJ. 2017;359:j4452. doi: 10.1136/bmj.j4452 pmid: 29074563

13. Royal College of Obstetricians and Gynaecologists. Thromboembolic Disease in Pregnancy and the Puerperium: Acute Management; Green-top Guideline No. 37b. 2015 [updated 2015; cited 2019]. Available from: https://www.rcog.org.uk/globalassets/documents/guideline s/gtg-37b.pdf.

14. Liatsikos SA, Tsikouras P, Manav B, Csorba R, von Tempelhoff GF, Galazios G. Inherited thrombophilia and reproductive disorders. J Turk Ger Gynecol Assoc. 2016;17(1):45-50. doi: 10.5152/jtgga.2016.15212 pmid: 27026779

15. Khan F, Vaillancourt C, Bourjeily G. Diagnosis and management of deep vein thrombosis in pregnancy. BMJ. 2017;357:j2344. doi: 10.1136/bmj.j2344 pmid: 28566284
16. ACOG Practice Bulletin No. 196: Thromboembolism in Pregnancy. Obstet Gynecol. 2018;132(1):e1-e17. doi: 10.1097/AOG.0000000000002706 pmid: 29939938

17. Ray JG, Vermeulen MJ, Bharatha A, Montanera WJ, Park AL. Association Between MRI Exposure During Pregnancy and Fetal and Childhood Outcomes. JAMA. 2016;316(9):952-61. doi: 10.1001/jama.2016.12126 pmid: 27599330

18. Chaturvedi S, McCrae KR. The antiphospholipid syndrome: still an enigma. Hematology Am Soc Hematol Educ Program. 2015;2015:53-60. doi: 10.1182/asheducation-2015.1.53 pmid: 26637701

19. Chan WS, Rey E, Kent NE, Group VTEiPGW, Chan WS, Kent $\mathrm{NE}$, et al. Venous thromboembolism and antithrombotic therapy in pregnancy. J Obstet Gynaecol Can. 2014;36(6):527-53. doi: 10.1016/S1701-2163(15)30569-7 pmid: 24927193

20. Ormesher L, Simcox LE, Tower C, Greer IA. 'To test or not to test', the arguments for and against thrombophilia testing in obstetrics. Obstet Med. 2017;10(2):61-6. doi: 10.1177/1753495X17695696 pmid: 28680464

21. Rodger MA, Gris JC, de Vries JIP, Martinelli I, Rey E, Schleussner E, et al. Low-molecular-weight heparin and recurrent placenta-mediated pregnancy complications: a metaanalysis of individual patient data from randomised controlled trials. Lancet. 2016;388(10060):2629-41. doi: 10.1016/S014 0-6736(16)31139-4 pmid: 27720497

22. Martens TZ, Emed JD. The experiences and challenges of pregnant women coping with thrombophilia.J Obstet Gynecol Neonatal Nurs. 2007;36(1):55-62. doi: 10.1111/j.15526909.2006.00113.x pmid: 17238947

23. Glover V. Maternal depression, anxiety and stress during pregnancy and child outcome; what needs to be done. Best Pract Res Clin Obstet Gynaecol. 2014;28(1):25-35. doi: 10.1016/j.bpobgyn.2013.08.017 pmid: 24090740

24. Fogerty AE. Management of Venous Thromboembolism in Pregnancy. Curr Treat Options Cardiovasc Med. 2018;20(8):69. doi: 10.1007/s11936-018-0658-3 pmid: 30039233

25. Middeldorp S. New studies of low-molecular-weight heparin in pregnancy. Thromb Res. 2015;135 Suppl 1:S26-9. doi: 10.1016/S0049-3848(15)50436-2 pmid: 25903529 